\title{
Retos del desarrollo de videojuegos en España
}

\author{
Carlos Iglesias Redondo \\ Secretario General de AEVI
}

En 2013, el consumo en el sector del videojuego en España (hardware, software y periféricos) alcanzó 762 millones de euros a través de la venta física, según los datos de Gfk ${ }^{1}$. En este periodo, los españoles compraron cerca de 11 millones de videojuegos, casi 1.200.000 consolas y unos 4,5 millones de periféricos.

En los últimos años el crecimiento exponencial del consumo de videojuegos en los nuevos canales de comercialización - online, redes sociales, y plataformas móviles-, está generando, a nivel mundial, un enorme crecimiento en el desarrollo de videojuegos. Para nuestro país supone una gran oportunidad de crecimiento en la producción de videojuegos.

Según los datos de Gametrack ${ }^{2}$ en España hay 14 millones de videojugadores, lo que significa que un $40 \%$ de la población española entre 6 y 65 años juega en algún momento de la semana a videojuegos, de los cuales, además, un $47 \%$ son mujeres. Estos datos significan que el videojuego ha llegado a una gran parte de la sociedad, llegando a cualquier persona sin importar edad, género o clase social.

Estos resultados consolidan al sector de los videojuegos como la primera industria de ocio audiovisual e interactivo en nuestro país, y a España como el cuarto mercado europeo del sector, por detrás de Reino Unido, Alemania y Francia.

1 Datos extraídos de AEVI: http://www.aevi.org.es/index.php?option=com_mtree\&task=att_download\&link_id=9\&cf_ $\mathrm{id}=30$

2 Datos extraídos de AEVI: http://www.aevi.org.es/aevi/noticias/226--cada-vez-hay-mas-mujeres-entre-los-14-millones-de-videojugadores-en-espana 
La industria de los videojuegos ofrece excelentes oportunidades de negocio, por lo que debería ser tratado como un sector estratégico de la economía española. Su defensa y promoción, sin duda, generará riqueza y amplias posibilidades de creación de empleo de calidad, especialmente en los jóvenes, lo que proporcionaría una alternativa profesional a un sector de la población lamentablemente castigada por el desempleo.

Para que esta oportunidad se convierta en realidad han de acometerse ciertos cambios y acciones, entre los que se encuentran los que proponemos a continuación.

\section{Incrementar la dimensión media de la empresa desarrolladora}

Las dimensiones reducidas de las empresas desarrolladoras en España impiden la acumulación de capital suficiente para crecer. Esta capacidad de crecimiento es necesaria para conseguir masa crítica suficiente para poner en valor sus intereses ante los poderes públicos e inversores particulares.

En numerosas ocasiones, los programas públicos de financiación o subvención parcial de proyectos quedan fuera de su alcance. No pueden movilizar siquiera los recursos complementarios necesarios para llevar a cabo estos proyectos financiables. De igual modo, no disponen de capacidad para promocionar su trabajo a nivel internacional o para conocer nuevos proyectos de editoras multinacionales.

Un tejido industrial compuesto por empresas de mayor tamaño mejoraría sus capacidades para participar en desarrollos de mayor presupuesto lo que, a su vez, favorecería su crecimiento.

En este sentido, sería positivo conseguir un foro sectorial con dimensión suficiente para atraer a las editoras y distribuidoras multinacionales.

\section{Mayor participación en la conversación sectorial}

Una mayor participación en la conversación sectorial puede mejorar la interactividad entre las diferentes asociaciones y sus asociados. Es necesario que exista una corriente positiva de diálogo. Aporta beneficios claros a los desarrolladores al entrar en contacto directo con las grandes distribuidoras y editoras multinacionales. También garantiza que los documentos de trabajo que puedan abordarse, contemplen los puntos de vista de los desarrolladores locales.

Finalmente, abre el acceso a servicios con los que no cuentan como empresa individual. Se trata, por ejemplo, de asesoría jurídica, de difusión de vías de financiación o de gabinete de prensa. 


\section{Organización de un Foro Nacional sobre Educación Superior en Software Interactivo}

Un Foro Nacional sobre Educación Superior en Software Interactivo en colaboración con las universidades, tanto públicas como privadas, que ofrecen titulaciones de grado y de postgrado en desarrollo de videojuegos. Deberá ser un espacio donde profesionales, académicos y estudiantes puedan debatir acerca de la industria nacional del software interactivo, las innovaciones y su aplicación en las aulas.

\section{Ampliar la capacidad de influencia}

No existe una vertebración adecuada para representar sus intereses ante la opinión pública y ante la Administración. El sector del desarrollo está compuesto por numerosas empresas de pequeño tamaño con escasos recursos que destinar a gestionar las relaciones externas. El asociacionismo no ha conseguido la agregación de intereses de manera adecuada. El hecho de establecer numerosas asociaciones nacionales ha dividido la interlocución. De igual modo, no se ha constituido una conexión entre las organizaciones nacionales y autonómicas, diluyendo la capacidad de influencia.

Esta situación ha favorecido que la interlocución se asiente sobre capacidades personales, representantes de los intereses particulares en lugar de los comunes de todos los desarrolladores.

Esta limitada capacidad de influencia ha provocado que se mantenga un perfil bajo ante los poderes públicos y no se haya transmitido la relevancia de apoyar al sector del desarrollo. Otros países con intereses mejor articulados han establecido numerosas medidas de incentivo orientadas a este sector - regulatorias, fiscales, de financiación, etc.-. Por el contrario, en España no se ha conseguido esta diferenciación y los sucesivos planes del Gobierno en materia TIC no atienden de manera específica las necesidades concretas de los desarrolladores.

\section{Favorecer la disponibilidad de profesionales especializados}

Como se ha puesto de manifiesto en numerosos encuentros sectoriales, uno de los principales problemas es la falta de personal cualificado. El problema radica en la poca adecuación de la oferta existente a las necesidades reales de las empresas - a pesar de que en los últimos años ha surgido cierta oferta de escuelas en la formación de profesionales en el desarrollo de videojuegos-, que se suma a la escasa sensibilidad de la Administración para acelerar la aprobación de las nuevas titulaciones que se están creando tras el Plan Bolonia. Esta aprobación permitiría que se multiplicara la oferta dando acceso a más estudiantes a la Universidad pública de titulaciones de grado. 
En los países de nuestro entorno, la adaptación de los currículos formativos está más avanzada, permitiendo a las empresas acceder al talento de manera más sencilla. Esta circunstancia hace que el crecimiento del tejido productivo se realice más rápido. Ante la contratación de nuevos proyectos, esas empresas tienen acceso a talento especializado en el mercado laboral, cosa que en España no sucede.

La formación continua es otra problemática a la que se debe dar respuesta. En un negocio en constante evolución como el de los videojuegos, las desarrolladoras precisan de herramientas de reciclado ágil y flexible para su personal.

\section{Visibilidad}

La ventaja que ofrece un mercado en el que los canales de distribución no requieren una determinada dimensión tiene como desventaja una oferta masiva, en la que difícilmente se hace reconocible un producto por sus virtudes, (calidad, innovación, originalidad, etc.) o por surgir en un entorno tremendamente competitivo, alcanzando frecuentemente la saturación. Se necesita de un apoyo que dé acceso a canales promocionales, a los medios de comunicación, a la inversión en proyectos - ya sea con recursos tanto públicos como privados-, al patrocinio de editores que tengan relación con las empresas de desarrollo. Aprovechar el auge de la gamificación, llegando a numerosos públicos y situaciones, demostrando capacidades más allá del ocio.

$* * *$

\section{Para contribuir al crecimiento de la industria del videojuego, nace AEVI.}

AEVI nació con el objetivo de representar a toda la cadena de producción del videojuego, convirtiéndose en una institución aglutinadora, que sume fuerzas, ideas, intereses y que haga industria.

Los principales objetivos de AEVI son:

1. Promover el desarrollo de la industria local en nuestro país, favoreciendo el atractivo de inversión en España y contribuyendo a la generación de riqueza y empleo en el sector del videojuego.

2. Colaborar con las Administraciones Públicas e instituciones decisoras en el desarrollo de programas e iniciativas para el impulso de una industria local del videojuego en España.

3. Defender los intereses de todos agentes implicados en la cadena de producción de la industria.

4. Velar por un modelo sostenible y de futuro para el sector, que pasa por la defensa de la propiedad intelectual y la innovación en las fórmulas de 
oferta y comercialización de productos en un entorno de convivencia entre el mercado físico y el online.

5. Seguir construyendo la reputación del videojuego ocio y gamificación, ya que el videojuego está cada vez más presente en nuestras vidas.

El reposicionamiento de aDeSe, ahora AEVI, como interlocutor global del sector empresarial del videojuego resulta de interés para los desarrolladores. La capacidad de influencia de AEVI ha quedado demostrada en los últimos años. La integración de los desarrolladores asegura que sus intereses formen parte de la conversación política, académica y sectorial.

Madrid Games Week, deberá convertirse en el punto de encuentro del desarrollo para que los videojuegos tomen cada vez más peso y protagonismo, visualizándose tanto en el programa de la feria como en las acciones especiales que se desarrollan. Para ello, es conveniente que AEVI concentre un número suficiente de compañías de desarrollo que le permita el reconocimiento de la nueva asociación como representante de la industria, logrando que Madrid abandere, a nivel internacional, el software interactivo español.

Sin embargo, como hemos comprobado, son muchos los encuentros sectoriales que se celebran en otras ciudades españolas y que sirven para reunir a las empresas locales. Es positivo apoyar estas ferias y encuentros, principalmente en ciudades como Barcelona, Valencia, Bilbao o Málaga, potenciando la territorialidad de estos clústers de empresas desarrolladoras. De esta forma podremos demostrar que la asociación engloba, representa y apoya a todos sus asociados y que está presente en todos los núcleos de innovación en software interactivo.

\section{Referencia de este artículo}

Iglesias Redondo, Carlos (2015). Retos del desarrollo de videojuegos en España. En: adComunica. Revista Científica de Estrategias, Tendencias e Innovación en Comunicación, $\mathrm{n}^{\circ}$ 9. Castellón: Asociación para el Desarrollo de la Comunicación adComunica, Universidad Complutense de Madrid y Universitat Jaume I, 197-201. DOI: http://dx.doi.org/10.6035/2174-0992.2015.9.14. 